ORIGINAL ARTICLE

\title{
The level of physical activity of university students in Slovakia during COVID - 19 pandemic
}

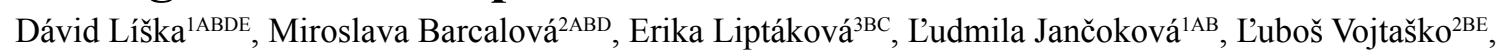
Daniel Gurín ${ }^{4 \mathrm{AB}}$

\author{
${ }^{1}$ Matej Bel University, Faculty of Arts, Department of Physical Education and Sports, Slovakia \\ ${ }^{2}$ Technical University of Košice, Department of Physical Education, Slovakia \\ ${ }^{3}$ Technical University of Košice, Faculty of Economics, Department of Applied Mathematics and Business Informat- \\ ics, Slovakia \\ ${ }^{4}$ Slovak Medical University in Bratislava, Faculty of Healthcare based in Banská Bystrica, Slovakia
}

Authors' Contribution: A - Study design; B - Data collection; C - Statistical analysis; D - Manuscript Preparation; E - Funds Collection

\begin{tabular}{|c|c|}
\hline \multicolumn{2}{|l|}{ Abstract } \\
\hline $\begin{array}{l}\text { Background } \\
\text { and Study Aim }\end{array}$ & $\begin{array}{l}\text { COVID-19 coronavirus pandemic has affected several areas of human and public life. The implementation } \\
\text { of the restrictions affects free movement, leading to limited physical activity (PA) level. The main aim of } \\
\text { the study was to determine the level of PA of university students in Slovakia during COVID-19 pandemics. }\end{array}$ \\
\hline $\begin{array}{l}\text { Material and } \\
\text { Methods }\end{array}$ & $\begin{array}{l}\text { The sample consisted of } 3128 \text { university students. Data was obtained from students from three universities } \\
\text { with different specializations. A questionnaire about lifestyle with questions about physical activity was } \\
\text { used. The questionnaire was distributed using online communication systems of universities. The online } \\
\text { questionnaire was answered by } 3128 \text { students. }\end{array}$ \\
\hline Results & $\begin{array}{l}\text { Analyzed data were obtained from } 3128 \text { students. The results indicate that } 38 \% \text { of all students exercise } \\
3-4 \text { times per week, while } 41 \% \text { exercise } 1-2 \text { times per week, and } 21 \% \text { do not exercise at all, or exercise } \\
1-2 \text { times per month. Found weak positive correlation }(r=0,337) \text { was between the exercise frequency and } \\
\text { perception of well-being, and a very weak positive correlation }(r=0,187) \text { between the exercise frequency } \\
\text { and stress intensity. A moderate positive correlation was found between the perception of health and life } \\
\text { energy }(r=0,579) \text {. A moderate positive correlation was observed between the perception of health and } \\
\text { physical strength }(r=0,579) \text {. }\end{array}$ \\
\hline $\begin{array}{l}\text { Conclusions } \\
\text { Keywords: }\end{array}$ & $\begin{array}{l}\text { COVID-19 restrictions have been associated with the reduction of physical activity of the students. To avoid } \\
\text { the negative effects of a sedentary lifestyle, it is necessary to promote activity among university students. } \\
\text { coronavirus, lifestyle, online communication, exercise, well-being }\end{array}$ \\
\hline
\end{tabular}

\section{Introduction}

The first cases of COVID-19 originally appeared in December 2019 in Wuhan, China, in Hubei Province, and the situation has quickly turned into a global pandemic [1]. The emergence of the global crisis COVID-19 has caused an immediate and significant burden on public health [2]. The COVID-19 pandemic has brought various challenges and changes to human life around the world, affecting the quality of life, lifestyles, and social life, and affected the local and international economy. In the early stages of the crisis, national governments took measures to reduce the spread of COVID-19, and many countries were constrained by various restrictions. Restrictions are likely to affect reducing physical activity [3]. Physical activity can be defined as any physical movement performed by skeletal muscle that requires energy expenditure. A subcategory of physical activity is exercising. It is a planned, repetitive activity aimed to improve or maintain any of the components of physical fitness. The beneficial effects of physical activity on human health are clear [4]. Lack of physical activity is associated with a higher risk of developing

\footnotetext{
๑ Dávid Líška, Miroslava Barcalová, Erika Liptáková,

L’udmila Jančoková, Ĺuboš Vojtaško, Daniel Gurín, 2021

doi:10.15561/26649837.2021.0505
}

diseases. Sufficient physical activity is associated with lower mortality [5]. Physical activity is important in the prevention of cardiovascular diseases [6]. The benefit of physical activity is also applied in the prevention and treatment of oncological diseases [7]. Lack of physical activity is associated with weight gain [8]. Lack of physical activity at a younger age often may not cause any acute manifestations, the health consequences may manifest with higher age. Some studies have shown a decrease in physical activity during the corona crisis [911]. The restrictions imposed were a major barrier for physical activity, the closure of sports facilities and parks has reduced, in particular, the possibility of engaging in physical activity. It can be assumed that eLearning and teleworking contribute additionally to a sedentary lifestyle. A sedentary lifestyle is associated with a higher risk of developing diseases [12]. It can be seen that the COVID-19 crisis has led to the limitation of physical activity not only for healthy people but also for patients [13].

For this reason, our study aimed to measure the level of physical activity of university students in Slovakia. We hypothesized that the establishment of eLearning and government restrictions will contribute to decreasing the overall level of physical activity. 


\section{Material and Methods}

To assess the impact of the COVID-19 pandemic and the effect of restrictions we decided to investigate the level of physical activity of Slovak university students. The study was cross-sectional at 3 Slovak universities: Matej Bel University, Technical University of Košice, Slovak Medical University in Bratislava Faculty of Healthcare based in Banská Bystrica. The data were collected through the online questionnaire for 2 months, from October to November 2020.

\section{Participants}

We have focused on university students aged 18 and over. Students were from three universities with different specifications. A lifestyle questionnaire was used, from which we used questions about physical activity. The questionnaire was distributed using online communication systems of universities. All participants agreed to participate in the study and informed consent was obtained from all of the subjects. All data were collected anonymously without providing any personal data and participants were not rewarded. We received 3128 students who answered the online questionnaire. Of these, $2238(71,5 \%)$ were students from Technical University of Košice., 620 (19,8\%) were students from Matej Bel University and $270(8,6 \%)$ were students from Slovak Medical University in Bratislava Faculty of Healthcare based in Banská Bystrica. 1689 men (54\%) and 1439 women $(46 \%)$ answered a questionnaire. The average age of the sample was $21,6(\mathrm{SD} \pm 4,4)$. The average age in the group of men was $21,3(\mathrm{SD} \pm 4)$ and in the group of women $22(\mathrm{SD} \pm 4,8)$.

\section{Questionnaire}

Questions were selected from the lifestyle questionnaire. We have focused on the questions about physical activity during the coronavirus crisis. The questionnaire included questions: "How often do you exercise during the coronavirus crisis?", What kind of exercise do you prefer?", "What kind of sport have you practiced in the past?", "Where do you go to exercise?", "What kind of movement activity do you dislike?" In the following questions, students could note their perceptions on a scale of 1 to 10 . "What level of stress have you been feeling recently?", "How healthy do you feel?", "In terms of your energy, how do you feel during the normal day?", "How strong you are physical?", "What are your coordination abilities?".

\section{Statistical analysis}

The frequencies of responses on categorical variables and ordinal variables were presented as numeric values and percentages). A non-parametric Mann-Whitney $\mathrm{U}$ test was conducted to test the hypothesis that the distributions of two populations (man vs. female) are equal. The strength of the dependence between ordinal variables was evaluated using Spearman's rank-order correlation coefficient. Statistical analysis was performed using Statistical Package for the Social Sciences - SPSS ver. 19.0 (IBM, Chicago, IL, USA). The threshold probability of $\mathrm{p}<0.05$ was taken as the level of statistical significance.

\section{Results}

The majority of students prefer aerobic exercises $(n=1330)$ and strength exercises $(n=1328) .328$ students prefer interval type of exercises. 142 students prefer none of the exercises (Table 1).

The least favorite type of movement activity was running $(38,4 \%)$. The second was football with $(7,1 \%)$ and the third weight training $(6,9 \%)$. The fourth least favorite type of movement activity was swimming (4,9\%). Except noted movement activities, students mentioned also other types of not favorite movement activity: zumba (1,5\%), hiking $(1,3 \%)$, exercises as push-ups, sit ups, plank, squat $(1,2 \%)$, skiing $(1 \%)$, interval training $(1 \%)$, cardio $(0,8 \%)$, walking $(0,76 \%)$, yoga $(0,71 \%)$, hockey $(0,55 \%)$, dancing $(0,50 \%)$, boxing, aikido, karate $(0,46 \%)$, inline skating $(0,42 \%)$, tennis $(0,34 \%)$, floorball $(0,29 \%)$, golf $(0,25 \%)$, climbing $(0,25 \%)$.

$38 \%$ of students exercise $3-4$ times per week, $41 \%$ of students exercise 1-2 times per week. $21 \%$ of students do not exercise at all or exercise just 1-2 times per month.

We have received the following answers to the question "What kind of sport have you practiced in the past?":

- Men: Most male students in the past played football $(\mathrm{n}=340)$, cycling was performed by 243 students, fitness 222, running 147, home training 119, hiking 97, swimming 74, volleyball 77, and inline skating was performed by 12 students. 305 students have mentioned other sport. No sport was mentioned by 43 students.

- Women: Most female students in the past have practiced home training $(\mathrm{n}=279)$, fitness training performed 185 students, running 184, hiking 124, swimming 120 , volleyball 104 , cycling 100 , inline skating 67, and football 36 students. 218 students have mentioned other sport. No sport was mentioned by 22 students.

The question "Where do you go to exercise?" was mostly answered that students do both: inside and outside training (45\%). Only inside training is performed by $25 \%$ of students, only outside training is performed by $25 \%$ of students. $5 \%$ of students do not exercise anywhere. Only outside training is performed by men $27 \%$ vs. $19 \%$ of women. Only inside training is performed by women $29 \%$ vs. $22 \%$ of men. $6 \%$ of men and $7 \%$ of women do not exercise anywhere.

In Table 1 we have noted perception of stress during the coronavirus crisis. Scale 1-10 was available for students to respond, thereby 1 was used for feeling without stress and 10 was used for maximum stress. Overall, the average level of stress perception was at level 5.11. Regarding the perception of stress, we were curious if there is a statistically significant difference between men and women. Using the Mann-Whitney test, we tested the hypothesis that the distributions of both populations are equal. The result of the test $(\mathrm{p}<0.05)$ declares that the difference between men and women is statistically significant - women perceive stress worse (average value 5.51) than men (average value 4.78). 
In Table 2 we recorded students " perception of wellbeing during the coronavirus crisis. $17 \%$ of students selected maximum wellbeing (value 10). $53 \%$ of students selected signs of wellbeing $(7,8$, resp. 9). The average value of wellbeing perception was 7.77 in total. It represents a value on the scale of 1 to 10 in the range of the third and fourth quartiles, and can therefore be described as positive. Regarding the perception of wellbeing, we were curious if there is a statistically significant difference between men and women. Using the Mann-Whitney test, we tested the hypothesis that the distributions of both populations are equal. The result of the test $(p<0.05)$ declares that the difference between men and women is statistically significant - women perceive wellbeing worse (average value 7. 56) than men (average value 7.94).

The assessment of students' perception of energy during the day was recorded. The average value was 7.13, which is a relatively high value located in the third quartile of the 10-point scale. When testing the differences between men and women in the distributions of their responses, we observed a statistically significant difference $(\mathrm{p}<0.05)$ : women perceive their energy (average value 6.91) worse than men (average value 7.34).

In Table 3, students answered the question of How strong do they feel physical, with meaning 1 as weak and 10 as full of strength. The average value was 7 in total (men 7.29, women 6.68). It indicates a positive evaluation of physical strength within the sample. Regarding the perception of physical strength, we were curious if there is a statistically significant difference between men and women. Using the Mann-Whitney test, we tested the hypothesis that the distributions of both populations are equal.

The result of the test $(\mathrm{p}<0.05)$ declares that the difference between men and women is statistically significant - women perceive their physical strength (average value 6.68) worse than men (average value 7.29).

In the last question, we asked how students perceive

Table 1. Students' responses regarding level of stress during corona crisis

\begin{tabular}{llll}
\hline Level of Stress & Male & Female & Total \\
\hline $\mathbf{1 0}$ (maximum) & $80(5 \%)$ & $66(5 \%)$ & $146(5 \%)$ \\
$\mathbf{9}$ & $58(3 \%)$ & $72(5 \%)$ & $130(4 \%)$ \\
$\mathbf{8}$ & $167(10 \%)$ & $175(12 \%)$ & $342(11 \%)$ \\
$\mathbf{7}$ & $192(11 \%)$ & $227(16 \%)$ & $419(13 \%)$ \\
$\mathbf{6}$ & $129(8 \%)$ & $168(12 \%)$ & $297(9 \%)$ \\
$\mathbf{5}$ & $239(14 \%)$ & $248(17 \%)$ & $487(16 \%)$ \\
$\mathbf{4}$ & $170(10 \%)$ & $151(10 \%)$ & $321(10 \%)$ \\
$\mathbf{3}$ & $273(16 \%)$ & $163(11 \%)$ & $436(14 \%)$ \\
$\mathbf{2}$ & $221(13 \%)$ & $116(8 \%)$ & $337(11 \%)$ \\
$\mathbf{1}$ & $160(9 \%)$ & $53(4 \%)$ & $213(7 \%)$ \\
\hline
\end{tabular}

Note: The first column shows the perception of stress: 10-maximum possible stress, 1-no stress. In the second and third columns the frequencies are relative and absolute for men and women separately and in the fourth column is cumulative frequency.

Table 2. Students' responses regarding of wellbeing feelings

\begin{tabular}{llll}
\hline Wellbeing feelings & Male & Female & Total \\
\hline $\mathbf{1}$ & $3(0.2 \%)$ & $2(0.1 \%)$ & $5(0.2 \%)$ \\
$\mathbf{2}$ & $6(0.3 \%)$ & $6(0.4 \%)$ & $12(0.4 \%)$ \\
$\mathbf{3}$ & $23(1.4 \%)$ & $25(1.8 \%)$ & $48(1.5 \%)$ \\
$\mathbf{4}$ & $40(2.3 \%)$ & $53(3.7 \%)$ & $93(3.0 \%)$ \\
$\mathbf{5}$ & $103(6.2 \%)$ & $135(9.4 \%)$ & $238(7.6 \%)$ \\
$\mathbf{6}$ & $118(6.9 \%)$ & $119(8.3 \%)$ & $237(7.5 \%)$ \\
$\mathbf{7}$ & $249(14.7 \%)$ & $275(19.1 \%)$ & $524(16.7 \%)$ \\
$\mathbf{8}$ & $458(27.1 \%)$ & $351(24.4 \%)$ & $809(25.9 \%)$ \\
$\mathbf{9}$ & $353(20.9 \%)$ & $270(18.8 \%)$ & $623(20.0) \%$ \\
10 & $336(19.9 \%)$ & $203(14.1 \%)$ & $539(17.3 \%)$ \\
\hline
\end{tabular}

Note: In the first column you can see the perception of wellbeing: 10 - I feel extremely good, 1- I feel bad. In the second and third columns, the frequencies are absolute and relative for men and women separately and in the fourth column is cumulative frequency. 
their coordination skills. They expressed it on a scale of 1 (uncoordinated) to 10 (coordinated). The average value in the sample was 7.92. The perception of men's coordination skills (average value 7.95) was statistically significantly higher than in women (average value 7.66).

In further analyzes, we focused on identifying possible dependencies between selected variables. Correlation between frequency of exercise and variables was evaluated: intensity of stress, perception of wellbeing, perception of energy, perception of physical strength, perception of coordination skills. Since all variables were ordinal, we used Spearman's rank-order correlation coefficient to calculate the strength and direction of the dependence. The results are shown in Table 4.

As can be seen in Table 9, in all cases there is positive dependence between frequency of exercise and variable. Intensity dependence is different: of five examined correlations, dependence between frequency of exercise and perception of wellbeing is the strongest, but this dependence is not strong $(\mathrm{r}=0,339)$. Dependence between frequency of exercise and stress intensity is the weakest, almost none $(\mathrm{r}=0,185)$.

We test the dependence between the perception of wellbeing and the perception of energy. Spearman's rank-order correlation coefficient $(\mathrm{r}=0,579)$ declares the moderate positive dependence $(r=0,579)$ (figure 1). Similarly, we noted positive dependence $(r=0,418)$ between the perception of wellbeing and physical strength (figure 2).

\section{Discussion}

The most important question for us was the question of the frequency of exercise during the week. The optimal number of exercises per week was stated by 38\% of students. A smaller number of exercises per week was reported by $62 \%$ of students. This number of exercises per week can put students at risk due to low physical activity, especially in the future. In the study, we focused on the students' level of stress. In our study men tolerate the current situation better than women. Stress is another negative factor that can contribute to reducing the physical activity of students. Increasing physical activity could be a beneficial factor in relieving stress caused by the coronavirus crisis [14]. With a lower level of stress of men, a better perception of wellbeing was found. Concerning men, we also noticed a feeling of higher energy during the day. The most popular type of physical activity for students was aerobic and strength training. Interval exercise was less popular. A surprising response to the question about the unpopularity of physical activity among students was running, which was marked by 913 students. This may be related to inappropriate education about the impact of physical activity since childhood. The physical activity preference results may help with creating online exercises for people at home with restrictions. Almost half of the students exercise both inside and outside. It is also caused by warmer weather. During the winter, this ratio is likely to change in favor of indoor exercise options. Education about appropriate home exercises could help increase

Table 3. Students' responses regarding of strong feelings

\begin{tabular}{llll}
\hline Feelings & Male & Female & Total \\
\hline $\mathbf{1}$ & $3(0.2 \%)$ & $3(0.2 \%)$ & $6(0.2 \%)$ \\
$\mathbf{2}$ & $6(0.4 \%)$ & $11(0.8 \%)$ & $17(0.5 \%)$ \\
$\mathbf{3}$ & $31(1.8 \%)$ & $52(3.6 \%)$ & $83(2.6 \%)$ \\
$\mathbf{4}$ & $56(3.3 \%)$ & $104(7.2 \%)$ & $160(5.0 \%)$ \\
$\mathbf{5}$ & $157(9.3 \%)$ & $205(14.2 \%)$ & $362(11.5 \%)$ \\
$\mathbf{6}$ & $228(13.5 \%)$ & $221(15.4 \%)$ & $449(14.3 \%)$ \\
$\mathbf{7}$ & $403(23.9 \%)$ & $363(25.2 \%)$ & $766(24.5 \%)$ \\
$\mathbf{8}$ & $422(25.0 \%)$ & $287(19.9 \%)$ & $709(22.8 \%)$ \\
$\mathbf{9}$ & $200(11.9 \%)$ & $104(7.2 \%)$ & $304(9.9 \%)$ \\
$\mathbf{1 0}$ & $183(10.8 \%)$ & $89(6.2 \%)$ & $272(8.8 \%)$ \\
\hline
\end{tabular}

Note: Rating in the first column: 10-full of strength, 1-weak. In the second and third columns, the frequencies are absolute and relative for men and women separately and in the fourth column is cumulative frequency.

Table 4. Correlation between the frequency of exercise and selected variables (in order of dependence of strength)

\begin{tabular}{llll}
\hline Correlation frequency of exercise & Male & Female & Total \\
\hline Wellbeing & 0.339 & 0.319 & 0.337 \\
Perception of energy & 0.313 & 0.325 & 0.287 \\
Physical strength & 0.310 & 0.294 & 0.319 \\
Coordination abilities & 0.217 & 0.210 & 0.212 \\
Stress intensity & 0.185 & 0.167 & 0.183 \\
\hline
\end{tabular}

Note: Numbers in the table declare values of Spearman's rank-order correlation coefficient 


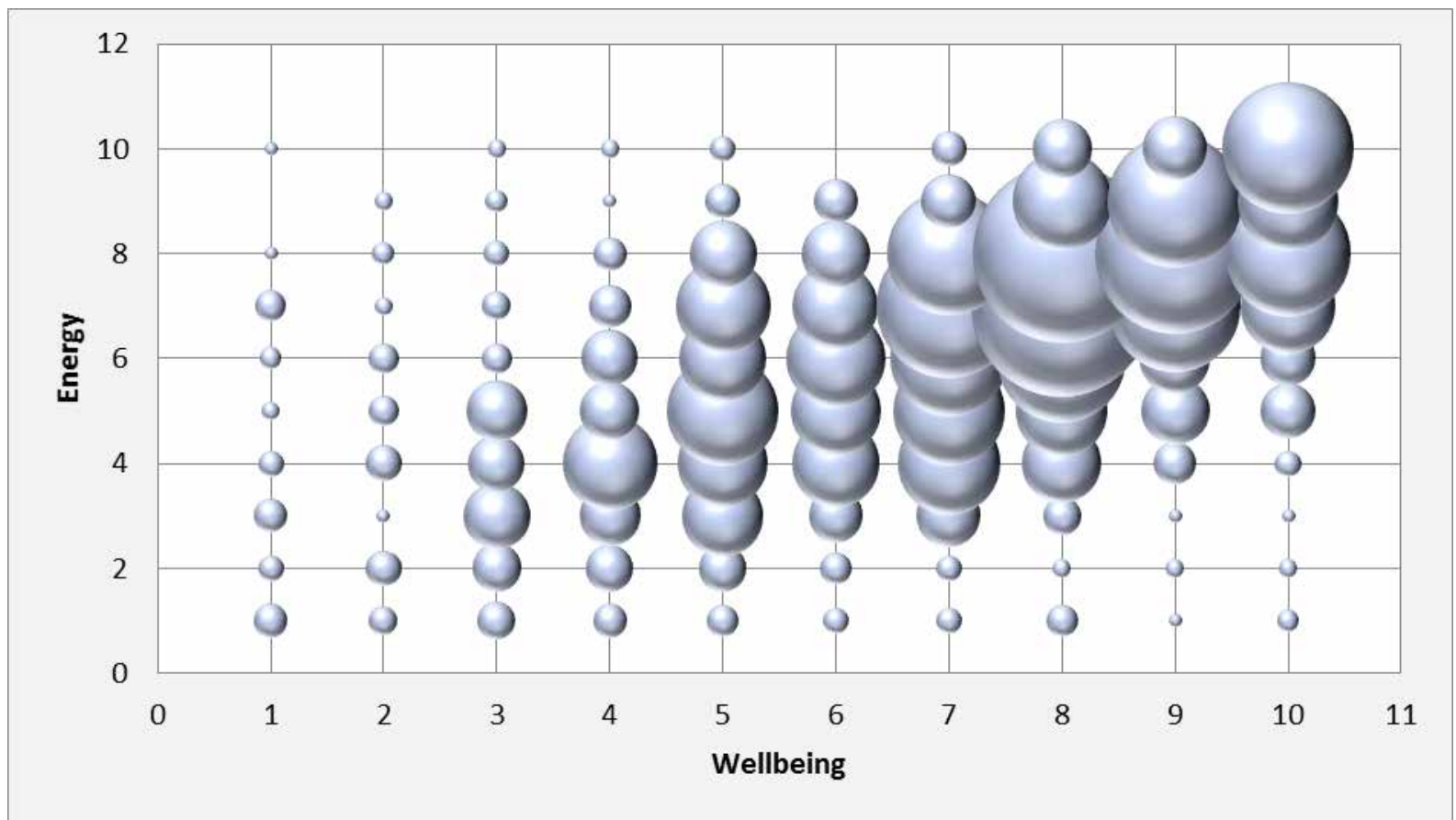

Note: Wellbeing (1-bad, 10 - extremely good), energy (1 - very weak, 10 - full of energy). Size of the bubble shows numbers of response of the relevant ranking combination.

Figure 1. Correlation between wellbeing and perception of energy

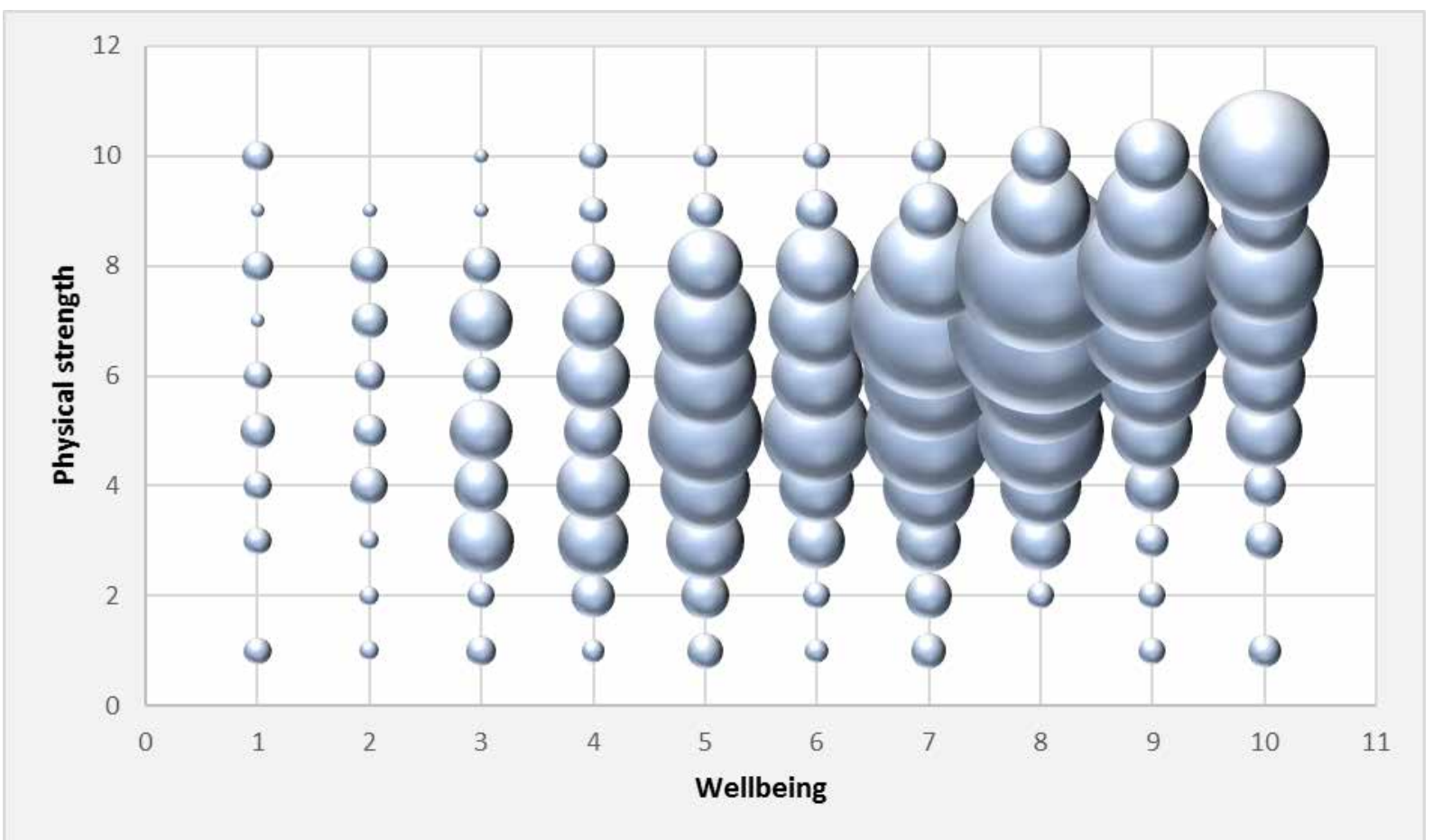

Note: Wellbeing ( 1 - bad, 10 - extremely good), physical strength (1-very weak, 10 - strong). Size of the bubble shows numbers of response of the relevant ranking combination.

Figure 2. Correlation between wellbeing and physical strength

physical activity during a pandemic and thus reduce the risk of chronic diseases due to low physical activity.

In preventing most chronic diseases, exercising plays a vital role. Our body needs a relatively long period to benefit from the healthy adaptations that exercising generates, modulated by various molecular mechanisms such as epigenetics, metabolic modulation, or decreased inflammation [15]. This means that efforts to maintain an active lifestyle during home quarantine should be necessary to avoid the physical consequences associated with low physical activity. Low physical activity consequences on human health are wide-spectrum. We can observe human metabolic consequences such as increased insulin resistance, total body fat, abdominal fat, and increased 
inflammatory cytokines [16]. All these factors are closely related to the development of metabolic syndrome, which in turn increases the risk of several chronic diseases [17]. Excessive energy intake without expenditure may be a likely mechanism that contributes to given pathogenesis. Progress of COVID19 infection of obese patients is associated with worse prognostic factors [18-20].

Husain and Ashkanani [21] evaluated the change in lifestyle during the corona crisis. The sample consisted of 415 adults. There was noted a decrease in fast food consumption $(\mathrm{p}<0.001)$. There was also noted a decrease in physical activity and an increase in time spent in a sedentary lifestyle. The number of hours of sleep during the day increased and the number of hours of sleep at night decreased.

The effect of the corona crisis on physical activity and dietary habits in Italy was tested by Di Renzo et al. [22]. The sample consisted of 3533 Italians aged 12 to 86 . Weight gain was noted in almost $48.6 \%$ of cases.

The level of physical activity increased slightly in $38.3 \%$ of people. A decrease in physical activity was also recorded among Italian students [23].

Lopez-Moreno et al. [24] tested the effect of the corona crisis on Spanish citizens. The sample consisted of 675 Spanish, of which $38.8 \%$ experienced gain weight during the coronavirus crisis. $31.1 \%$ experienced weight loss. Weight gain correlated with age $(\mathrm{Rs}=0.14, p<$ $0.05)$. Less quality sleep was connected to higher BMI and age $(\mathrm{Rs}=-0.18, p<0.05)$ resp. $(\mathrm{Rs}=-0.21, p<0.05)$. $44,7 \%$ did not exercise during the crisis.

Robinson et al. [1] tested the impact of the coronavirus crisis on lifestyle factors in the United Kingdom ( $\mathrm{n}=2002)$. $56 \%$ of British reported deteriorated eating and worse exercise habits and weight loss problems than before the crisis. Higher British BMI correlated with lower physical activity and nutritional quality.

Lifestyle changes were also verified in the United Arab Emirates in a study by Ismail et al. [10]. The group consisted of 1012 adults. Weight gain was noted in 31\%. In addition, $38.5 \%$ did not engage in physical activity and $36.2 \%$ spent more than five hours a day on screens. A significantly higher percentage of participants reported physical exhaustion, emotional exhaustion, irritability, and tension during a pandemic compared to the prepandemic period $(\mathrm{p}<0.001)$. During a pandemic, sleep disorders predominated in $60.8 \%$ of participants. The impact of restrictions on physical activity was tested by Srivastav et al. [25]. The sample consisted of 143 students and physiotherapists. Overall physical activity before the lockdown was on average 7809.7 (3849.711769.8) MET-min/week and during the lockdown, it decreased to MET-min/week and 4135.7 (867.2-7404.1) MET-min/week; $p<0.0001$. While energy expenditure before and during COVID-19 lockdown period was 8189.8 (4242.1-12137.6) kcal/wk and 4221.7 (1004.67438.8) kcal/wk; p < 0.0001). Rutkowska et al. [26] compare physical activity during restrictions and the "unfreezing" stage. The study group consisted of 89 healthy Polish students. The average total PA rate during the first measurement was $8640 \mathrm{MET}-\mathrm{min} /$ week and in the second 10560 MET-min/week. The analysis of total energy expenditure showed a statistically significant difference $(\mathrm{p}<0.029)$. The establishment of "unfreezing" laws for sport and recreation and the reduction of restrictions have significantly contributed to an increase in the overall level of physical activity. In Poland, weight gain has been reported in $30 \%$ of people and weight loss in $18 \%$ [27]. A decrease in physical activity was also recorded in Greece [28].

Our study has several limitations that are associated with the design of the study. When completing the questionnaire, there could be a selection bias and the questionnaire may have been filled in by students who tend to do physical activity. Another limitation was the verifiability of the factors. Based on an online questionnaire, we could not verify the students' statements. Another limitation was the lack of basic data about a physical activity before coronavirus crisis, to objectively compare the effect of coronavirus crisis on the reduction of physical activity. Bias towards several questions as a level of coordination abilities could have resulted. The issue of coordination abilities is challenging and requires more objective measurement.

\section{Conclusions}

Low physical activity of Slovak university students during the COVID-19 pandemics was recorded. To avoid negative effects of a sedentary lifestyle, it is necessary to promote activity among university students.

\section{Funding}

No funds were provided.

\section{Conflict of Interest}

The authors declare that they have no conflicts of interest regarding the publication of this article.

\section{Adherence to Ethical Standards}

All procedures performed in studies involving human participants were in accordance with the ethical standards of the institutional and/or national research committee and with the 1964 Helsinki Declaration and its later amendments or comparable ethical standards. Informed consent was obtained from all individual participants involved in the study.

\section{Key points}

- COVID-19 pandemics is associated with a low level of physical activity in Slovak students.

- Emergency plan for treatment COVID-19 should contain guidelines for physical activity.

- To avoid the negative effects of a sedentary lifestyle, it is necessary to promote activity among university students. 


\section{References}

1. Robinson E, Gillespie S, Jones A. Weight-related lifestyle behaviours and the COVID-19 crisis: An online survey study of UK adults during social lockdown. Obes Sci Pract, 2020;6:735-40. https://doi.org/10.1002/osp4.442

2. Erenler AK, Baydin A. Challenges in COVID-19 diagnosis. Bratisl Lek Listy, 2020;121:864-864. https://doi.org/10.4149/BLL_2020_142

3. Ozen G, Koc H, Aksoy C. Health anxiety status of elite athletes in COVID-19 social isolation period. Bratisl Lek Listy. 2020;121(12):888-93. https://doi.org/10.4149/BLL_2020_146

4. Lieberman DE. Is Exercise Really Medicine? An Evolutionary Perspective. CurrentSports MedicineReports, 2015;14:313-9. https://doi.org/10.1249/JSR.0000000000000168

5. Kelly P, Kahlmeier S, Götschi T, Orsini N, Richards J, Roberts $\mathrm{N}$, et al. Systematic review and meta-analysis of reduction in all-cause mortality from walking and cycling and shape of dose response relationship. Int J Behav Nutr Phys Act, 2014;11:132. https://doi.org/10.1186/s12966-014-0132-x

6. Carnethon MR. Physical Activity and Cardiovascular Disease: How Much Is Enough? American Journal of Lifestyle Medicine, 2009;3:44S-49S. https://doi.org/10.1177/1559827609332737

7. Je Y, Jeon JY, Giovannucci EL, Meyerhardt JA. Association between physical activity and mortality in colorectal cancer: A meta-analysis of prospective cohort studies: Physical activity and colorectal cancer mortality. Int $J$ Cancer, 2013;133:1905-13. https://doi.org/10.1002/ijc.28208

8. Cuschieri S, Grech S. Obesity population at risk of COVID-19 complications. Glob Health Epidemiol, 2020;5:e6. https://doi.org/10.1017/gheg.2020.6

9. Ammar A, Brach M, Trabelsi K, Chtourou H, Boukhris O, Masmoudi L, et al. Effects of COVID-19 Home Confinement on Eating Behaviour and Physical Activity: Results of the ECLB-COVID19 International Online Survey. Nutrients, 2020;12:1583. https://doi.org/10.3390/nu12061583

10.Cheikh Ismail L, Osaili TM, Mohamad MN, Al Marzouqi A, Jarrar AH, Abu Jamous DO, et al. Eating Habits and Lifestyle during COVID-19 Lockdown in the United Arab Emirates: A Cross-Sectional Study. Nutrients, 2020;12:3314. https://doi.org/10.3390/nu12113314

11.Caputo EL, Reichert FF. Studies of Physical Activity and COVID-19 During the Pandemic: A Scoping Review. Journal of Physical Activity and Health, 2020;17:1275-84. https://doi.org/10.1123/jpah.2020-0406

12.Dempsey PC, Matthews CE, Dashti SG, Doherty AR, Bergouignan A, van Roekel EH, et al. Sedentary Behavior and Chronic Disease: Mechanisms and Future Directions. Journal of Physical Activity and Health, 2020;17:52-61. https://doi.org/10.1123/jpah.2019-0377

13.Di Stefano V, Battaglia G, Giustino V, Gagliardo A, D'Aleo M, Giannini $O$, et al. Significant reduction of physical activity in patients with neuromuscular disease during COVID-19 pandemic: the long-term consequences of quarantine. J Neurol, 2021;268:20-6. https://doi.org/10.1007/s00415-020-10064-6

14.Blumenthal JA, Smith PJ, Hoffman BM. Is Exercise a Viable Treatment for Depression? ACSMs Health Fit J. 2012;16(4):14-21. https://doi.org/10.1249/01.FIT.0000416000.09526.eb

15.Barrón-Cabrera E, Ramos-Lopez O, González-Becerra K, Riezu-Boj JI, Milagro FI, Martínez-López E, et al.
Epigenetic Modifications as Outcomes of Exercise Interventions Related to Specific Metabolic Alterations: A Systematic Review. Lifestyle Genomics 2019;12:25-44. https://doi.org/10.1159/000503289

16.Martinez-Ferran M, de la Guía-Galipienso F, Sanchis-Gomar F, Pareja-Galeano H. Metabolic Impacts of Confinement during the COVID-19 Pandemic Due to Modified Diet and Physical Activity Habits. Nutrients, 2020;12:1549. https://doi.org/10.3390/nu12061549

17.Rao DP, Dai S, Lagacé C, Krewski D. Metabolic syndrome and chronic disease. Chronic Dis Inj Can. 2014;34(1):36-45. https://doi.org/10.24095/hpcdp.34.1.06

18.Huang Y, Lu Y, Huang Y-M, Wang M, Ling W, Sui Y, et al. Obesity in patients with COVID-19: a systematic review and meta-analysis. Metabolism, 2020;113:154378. https://doi.org/10.1016/j.metabol.2020.154378

19.Kwok S, Adam S, Ho JH, Iqbal Z, Turkington P, Razvi S, et al. Obesity: A critical risk factor in the COVID -19 pandemic. Clin Obes, 2020;10. https://doi.org/10.1111/cob.12403

20.Caussy C, Wallet F, Laville M, Disse E. Obesity is Associated withSevereFormsofCOVID-19.Obesity, 2020;28:1175-1175. https://doi.org/10.1002/oby.22842

21.Husain W, Ashkanani F. Does COVID-19 change dietary habits and lifestyle behaviours in Kuwait: a community-based cross-sectional study. Environ Health Prev Med, 2020;25:61. https://doi.org/10.1186/s12199-020-00901-5

22.Di Renzo L, Gualtieri P, Pivari F, Soldati L, Attinà A, Cinelli $\mathrm{G}$, et al. Eating habits and lifestyle changes during COVID-19 lockdown: an Italian survey. J Transl Med. 2020;18(1):229. https://doi.org/10.1186/s12967-020-02399-5

23.Luciano F, Cenacchi V, Vegro V, Pavei G. COVID-19 lockdown: Physical activity, sedentary behaviour and sleep in Italian medicine students. European Journal of Sport Science, 2020:1-10. https://doi.org/10.1080/17461391.2020.1842910

24.López-Moreno M, López MTI, Miguel M, GarcésRimón M. Physical and Psychological Effects Related to Food Habits and Lifestyle Changes Derived from COVID-19 Home Confinement in the Spanish Population. Nutrients, 2020;12:3445. https://doi.org/10.3390/nu12113445

25.Srivastav AK, Sharma N, Samuel AJ. Impact of Coronavirus disease-19 (COVID-19) lockdown on physical activity and energy expenditure among physiotherapy professionals and students using web-based open E-survey sent through WhatsApp, Facebook and Instagram messengers. Clinical Epidemiology and Global Health, 2021;9:78-84. https://doi.org/10.1016/j.cegh.2020.07.003

26.Rutkowska A, Kacperak K, Rutkowski S, Cacciante L, Kiper P, Szczegielniak J. The Impact of Isolation Due to COVID-19 on Physical Activity Levels in Adult Students. Sustainability, 2021;13:446. https://doi.org/10.3390/su13020446

27.Sidor A, Rzymski P. Dietary Choices and Habits during COVID-19 Lockdown: Experience from Poland. Nutrients, 2020;12:1657. https://doi.org/10.3390/nu12061657

28.Bourdas DI, Zacharakis ED. Evolution of changes in physical activity over lockdown time: Physical activity datasets of four independent adult sample groups corresponding to each of the last four of the six COVID-19 lockdown weeks in Greece. Data in Brief, 2020;32:106301. https://doi.org/10.1016/j.dib.2020.106301 


\section{Information about the authors:}

Dávid Líška; (Corresponding Author); https://orcid.org/0000-0002-5700-1341; david.liska27@gmail.com; Department of Physical Education and Sports, Faculty of Arts, Matej Bel University; Banská Bystrica, Slovakia.

Miroslava Barcalová; https://orcid.org/0000-0003-2393-7085; miroslava.barcalova@tuke.sk; Department of Physical Education, Technical University of Košice; Košice, Slovakia.

Erika Liptáková; https://orcid.org/0000-0002-6016-0757; erika.liptakova@tuke.sk; Department of Applied Mathematics and Business Informatics, Faculty of Economics, Technical University of Košice; Košice, Slovakia.

Ludmila Jančoková; https://orcid.org/0000-0002-8435-2673; Ludmila.Jancokova@umb.sk; Department of Physical Education and Sports, Faculty of Arts, Matej Bel University; Banská Bystrica, Slovakia.

Luboš Vojtaško; https://orcid.org/0000-0003-3835-0463; lubos.vojtasko@tuke.sk; Department of Physical Education, Technical University of Košice; Košice, Slovakia.

Daniel Gurín; https://orcid.org/0000-0001-8796-9110; daniel.gurin@szu.sk; Faculty of Healthcare based in Banská Bystrica, Slovak Medical University in Bratislava; Bratislava, Slovakia.

Cite this article as:

Liška D, Barcalová M, Liptáková E, Jančoková L’, Vojtaško L', Gurín D. The level of physical activity of university students in Slovakia during COVID - 19 pandemic Pedagogy of Physical Culture and Sports, 2021;25(5):305-312.

https://doi.org/10.15561/26649837.2021.0505

This is an Open Access article distributed under the terms of the Creative Commons Attribution License, which permits unrestricted use, distribution, and reproduction in any medium, provided the original work is properly cited (http://creativecommons.org/licenses/by/4.0/deed.en).

Received: 01.07.2021

Accepted: 17.08.2021; Published: 30.10.2021 